\title{
Relationship Among Genes Conferring Partial Resistance to Leaf Rust (Puccinia triticina) in Wheat Lines CI 13227 and L-574-1
}

\author{
Jeffrey S. Lehman, Karin A. Hanson, and Gregory Shaner
}

First and second authors: Department of Life and Earth Sciences, Otterbein College, Westerville, OH 43081; and third author: Department of Botany and Plant Pathology, Purdue University, West Lafayette, IN 47907. Accepted for publication 15 October 2004.

\section{ABSTRACT}

Lehman, J. S., Hanson, K. A., and Shaner, G. 2005. Relationship among genes conferring partial resistance to leaf rust (Puccinia triticina) in wheat lines CI 13227 and L-574-1. Phytopathology 95:198-205.

This study describes the segregation of genes for resistance to the fungus Puccinia triticina in a cross between partially resistant wheat lines L-574-1 and CI 13227 with two and four genes for resistance, respectively. The objectives of this study were to use parental, $F_{1}, F_{2}$, and backcross populations to quantify maternal effects, degree of dominance, and transgressive segregation, and to determine whether CI 13227 and L-5741 share any resistance genes for long latent period or small uredinia. In two experiments conducted in the greenhouse, the uppermost leaf of adult wheat plants was inoculated prior to heading with $P$. triticina. On days 6 to 21 after inoculation, the number of uredinia that erupted from the leaf surface was counted and used to calculate the mean latent period (MLP). The length and width of five arbitrarily selected uredinia were measured and used to calculate uredinium area. Midparent values, degree of dominance, and broad-sense heritability were calculated for MLP and uredinium area. For experiment A, MLP values for CI 13227, L-574-1, $F_{1}$, and $F_{2}$ generations were $12.2,10.5,10.2$, and 10.6 days, respectively. For experiment B, MLP values for CI 13227, L-574-1, $\mathrm{F}_{1}, \mathrm{~F}_{2}$, backcross to CI 13227, and backcross to L-574-1 were $12.3,10.0,10.6,10.8,11.1$, and 10.0 days, respectively. The inheritance of long latent period was partially recessive, and no maternal effect was present $(P=0.62$ to 0.87 for the comparison of means in reciprocal crosses). Broad-sense heritability for MLP ranged from 0.72 to 0.74 , and there was transgressive segregation in the $\mathrm{F}_{2}$ and backcross populations. Uredinia of the $\mathrm{F}_{1}$ generation were slightly larger than uredinia for CI 13227. The inheritance of uredinium size was partially dominant, and no maternal effect was present $(P=0.5$ to 0.63$)$. Broad-sense heritability for uredinium area ranged from 0.36 to 0.73 and transgressive segregation was present in the $F_{2}$ and backcross populations. The results for MLP indicate that lines CI 13227 and L-574 likely share one gene for resistance (based on $\mathrm{F}_{1}$ values) but not two genes (based on the presence of transgressive segregation). CI 13227 and L 574-1 appear to have at least one gene difference for uredinium area. The linear relationship between uredinium area regressed onto MLP was significant $(P<0.001)$ and $r^{2}$ values ranged from 0.14 to 0.26 . These results indicate that the resistance in CI 13227 and L-574-1 could be combined to create wheat cultivars with greater partial resistance than that possessed by either parent based on MLP or uredinium size.

Additional keywords: slow rusting, Triticum aestivum.
Slow leaf rusting is a partial, quantitative form of resistance in wheat that retards the establishment and reproduction of the fungus Puccinia triticina. On partially resistant cultivars, there is a longer time between infection and production of secondary inoculum (i.e., a longer latent period) than on susceptible cultivars (19, $22,29,30)$. In addition, uredinia of the fungus often are smaller $(22,29,30)$, produce fewer spores $(19,27,30)$, and are fewer in number $(19,22,29,30)$. These components of resistance greatly reduce the rate of disease development in the field because $P$. triticina is a polycyclic pathogen $(4,7,29)$. As a result, partially resistant cultivars slow, but do not completely inhibit, the spread of leaf rust. Disease is held to levels that are economically less harmful to grain production.

There are several reports on the inheritance of slow leaf-rusting in cereals to various rust pathogens in crosses between (i) susceptible and resistant cultivars and (ii) resistant and resistant cultivars $(1-3,5,7-9,11,13,14,18,20,21,23,24,33)$. In several of these studies, inheritance of slow rusting was determined by measuring rust development in the field; in others, the inheritance of the components of slow rusting (e.g., latent period) was investigated. Slow rusting or its components generally proves to be a partially recessive trait. In several studies, the number of factors associated with slow rusting was estimated to be in the range of two or three,

Corresponding author: J. S. Lehman; E-mail address: jlehman@otterbein.edu

DOI: 10.1094/PHYTO-95-0198

(c) 2005 The American Phytopathological Society although in one study (7) much higher estimates were obtained. Heritability estimates are moderately high, often in the range of 0.6 to 0.9 .

Studies on the inheritance of resistance based on resistant $x$ resistant crosses often prove to be more difficult to interpret than studies based on susceptible $\times$ resistance crosses because the assumptions of many of the methods of analysis (i.e., joint scaling analysis and estimation of genes number based on Wright's formula) are violated due to lack of equal effects of genes, lack of unilateral distribution of plus alleles, and presence of interallelic interactions $(1,28,34)$. Also, the inheritance effects in one resistant parent can influence the effects of inheritance in the other resistant parent. Despite these shortcomings, crosses between two resistant parents are necessary for determining whether the parents share common genes and for describing gene action between the two parents.

Broers and Jacobs (3) estimated the number of genes for long latent period in susceptible $(\mathrm{cv}$. Little $\mathrm{Club}) \times$ resistant and resistant $\times$ resistant crosses of spring wheat cvs. Westphal $12 \mathrm{~A}$, Akabuzu, and BH1146 based on the frequency of recovery of parental phenotypes. They estimated that Westphal 12A, Akabuzu, and BH1146 carry three, two, and two or three genes for long latent period, respectively. They also observed transgressive segregation (i.e., latent periods longer and shorter than each parent) in their analysis of $F_{3}$ and $F_{5}$ generations of resistant $\times$ resistant crosses. They concluded that Westphal 12A and Akabozu have different genes governing long latent period, whereas Akabozu and $\mathrm{BH} 1146$ share at least one gene for long latent 
period. Jacobs and Broers (8) also made crosses between the partially resistant cvs. Westphal 12A, Akabuzu, and BH1146. Resistance was partially recessive and mean latent period of the $\mathrm{F}_{1}$ generation resembled the latent period of the less-resistant parent.

Bjarko and Line (2) reported additive gene action for partial resistance with significant interaction components in spring wheat cvs. Borah and Wampum. Their data failed to meet one of the assumptions of their method of analysis (joint scaling tests); namely, that all "plus" alleles for the character are associated with one parent and all "minus" loci are associated with the other parent. In a separate study, Bjarko and Line (1) reported on the number of genes controlling partial resistance and the heritability of partial resistance in resistant $\times$ resistant crosses between wheat cvs. Borah and Wampum. They estimated the number of genes segregating to be 5.7 to 8.6 when they used phenotypic range as a measure of genotypic range and 0 and 0.7 when they used parental difference as a measure of genotypic range. The phenotypic range method and the parental difference method are prone to overestimating and underestimating, respectively, the number of genes. The authors also observed transgressive segregation in a resistant $\times$ resistant cross between Borah and Wampum and suggested that different genes control the partial resistance in these cultivars.

Lee and Shaner (14) investigated partially resistant cultivars of diverse origin to determine if they possess unique genes for latent period. The latent period distributions of $F_{2}$ populations of all crosses between partially resistant cultivars were continuous and showed transgressive segregation. In four of the seven crosses, the $F_{1}$ latent period values were the same or longer than those of the less resistant parents. Lee and Shaner proposed that the longer latent periods in the $F_{1}$ populations were due to modifiers, epitasis, or complementation in the heterozygous state.

The number of genes for long latent period in cvs. CI 13227 and L-574-1 previously has been estimated $(13,28)$; however, there is no evidence that clearly shows whether CI 13227 and L574-1 share any genes that govern length of latent period and area of uredinia. These cultivars do not share common parents in their pedigree; however, they may have inherited the same genes for partial resistance from more distant ancestors. In previous studies, it was observed that populations of $P$. triticina that were selected for greater fitness on partially resistant CI 13227 also were more fit (i.e., larger initial uredinia and growth rate, and greater sporulation) on the partially resistant L-574-1 to which the pathogen had never been exposed (17). If the genes for long latent period in CI 13227 and L-574-1 are the same, then pathogen adaptation to CI 13227 likely would result in pathogen adaptation to L-574-1. In contrast, if the genes for resistance are different, then pathogen adaptation to CI 13227 would be specific and have little effect on the resistance of L-574-1, and crosses between CI 13227 and L-574-1 may produce progeny that are more resistant than either parent.

The objective of this research was to determine if the genes for partial resistance to $P$. triticina in CI 13227 are the same as those in L-574-1. Specifically, this study was designed to describe the mean latent period and uredinium area of parental, $F_{1}, F_{2}$, and backcross populations from crosses between L-574-1 and CI 13227. Distributions of segregating progeny were used to determine the presence of transgressive segregation, the number of shared genes, heritability, and degree of dominance for latent period and uredinium size.

\section{MATERIALS AND METHODS}

Wheat cultivars and genetic crosses. The inheritance of partially resistant wheat cultivars (Triticum aestivum L. em. Thell) CI 13227 and L-574-1 were studied in parental, $F_{1}, F_{2}$, and backcross populations. The pedigree of CI 13227 is Wabash/American
Banner//Klein Anniversario (28). L-574-1 was derived from a cross between cvs. Wakeland and Blueboy.

CI 13227 and L-574-1 were crossed in the greenhouse to produce $F_{1}$ seed. A portion of the $F_{1}$ progeny was grown in the greenhouse and allowed to self to produce $\mathrm{F}_{2}$ seed. The remaining $\mathrm{F}_{1}$ progeny were backcrossed to both parents to produce two backcross populations. Parental lines, $\mathrm{F}_{1}, \mathrm{~F}_{2}$, and backcross populations were evaluated for components of resistance in the greenhouse. The experiment was repeated (experiments A and B).

Seed of parental, $F_{1}, F_{2}$, and backcross generations were planted in flats of soil/peat (50:50). Seed were allowed to germinate and grow for 2 weeks. Wheat seedlings were vernalized at $3^{\circ} \mathrm{C}$ with $12 \mathrm{~h} /$ day of fluorescent light in a growth chamber for 8 weeks. The vernalized seedlings were transplanted individually into 400-ml plastic pots containing a soil/peat mixture, and moved to the greenhouse for inoculation with $P$. triticina and for evaluation of uredinium number and uredinium size.

Fungal cultures and inoculation procedure. The fungal population 851-WT was used to inoculate the parental, $\mathrm{F}_{1}, \mathrm{~F}_{2}$, and backcross populations. 851-WT is a naturally occurring Indiana population of $P$. triticina that was collected from 200 to 300 uredinia from volunteer seedlings of wheat cv. Beau (CI 17420) on 20 November 1984 at the Purdue Agronomy Farm, West Lafayette, IN. This population was increased for one generation on susceptible cv. Morocco and stored at $-80^{\circ} \mathrm{C}$ until use.

The flag leaf of each plant was inoculated with spores of $P$. triticina suspended in light mineral oil (400 $\mathrm{mg}$ spores per $400 \mathrm{ml}$ of mineral oil). Spores were sprayed onto plants with a model 151 Devilbiss atomizer and 552 to $620 \mathrm{kPa}$ air stream. Inoculated plants were placed in a moist chamber at 18 to $22^{\circ} \mathrm{C}$. After 12 to $14 \mathrm{~h}$, the plants were moved to the greenhouse at 18 to $22^{\circ} \mathrm{C}$.

Measuring components of host resistance. From 6 to 21 days after inoculation, we counted erupted uredinia on the upper surface of the middle 3 to $5 \mathrm{~cm}$ of the flag leaf. Based on the daily numbers of uredinia, the mean latent period (MLP) of parental, $\mathrm{F}_{1}, \mathrm{~F}_{2}$, and backcross populations was calculated with a weighted mean average. MLP, the average time required for uredinia to erupt, was calculated from counts of uredinia based on the equation

$$
\mathrm{MLP}=\sum_{i=6}^{n} P_{i} t_{i}
$$

in which $P_{i}$ is the proportion of uredinia on the $i$ th day after inoculation relative to the final number of uredinia, $t_{i}$ is the day after inoculation, and $n$ is the number of days after inoculation when all uredinia have appeared.

Five arbitrarily selected uredinia on individual flag leaves of each cultivar were marked, and their length (L) and width (W) were measured to the nearest tenth of a millimeter with a Bausch \& Lomb (Rochester, NY) measuring magnifier on day 18 after inoculation. From these dimensions, uredinium area (UA) was calculated using the equation for the area of an ellipse: UA = $[(\mathrm{L})(\mathrm{W})(\pi)] / 4$.

Data analysis. MLP and uredinium area in the $F_{1}$ and backcross populations were examined for maternal effects. We used $t$ tests to compare means of reciprocal crosses (i.e., L-574- $1 \times$ CI 13227 versus CI $13227 \times$ L-574-1) for statistical differences (31).

The degree of dominance by which MLP and uredinium area were expressed was calculated (6). Broad-sense heritability $(H)$ was calculated using the equation given by Kelly and Bliss (10) with corrections made by Shaner et al. (28): $H=\left(s_{\mathrm{F} 2}^{2}-\left[s_{\mathrm{P} 1}^{2}+s_{\mathrm{P} 2}^{2}+\right.\right.$ $\left.\left.s_{\mathrm{F} 1}^{2}\right] / 3\right) / s_{\mathrm{F} 2}^{2}$, in which $s_{\mathrm{F} 2}^{2}, s_{\mathrm{P} 1}^{2}, s_{\mathrm{P} 2}^{2}$, and $s_{\mathrm{F} 1}^{2}$ were the variances of the $\mathrm{F}_{2}, \mathrm{P}_{1}$ (L-574-1), $\mathrm{P}_{2}$ (CI 13227), and $\mathrm{F}_{1}$ populations, respectively.

Following the methods employed by Broers and Jacobs (3) and Bjarko and Line (1), the estimated number of shared genes or gene differences for MLP and uredinium area were calculated 
using Wright's formula (34). We used this method to calculate gene number based on (i) data from the backcross to the more resistant parent (CI 13227) and (ii) data from the $\mathrm{F}_{2}$ generation. The equations for calculating gene number for the backcross $\left(n_{\mathrm{BCP} 2}\right)$ and $\mathrm{F}_{2}$ generation $\left(n_{\mathrm{F} 2}\right)$ were $n_{\mathrm{BCP} 2}=(\mathrm{GR})^{2} /\left\{4\left[V_{\mathrm{BCP} 2}-\left(V_{\mathrm{P} 2}+\right.\right.\right.$ $\left.\left.\left.V_{\mathrm{F} 1}\right) / 2\right]\right\}$ and $n_{\mathrm{F} 2}=\left\{(\mathrm{GR})^{2}[1.5-2 h(1-h)]\right\} /\left\{8\left[V_{\mathrm{F} 2}-\left(V_{\mathrm{P} 1}+V_{\mathrm{P} 2}+\right.\right.\right.$ $\left.\left.\left.2 V_{\mathrm{F} 1}\right) / 4\right]\right\}$, in which $V_{\mathrm{P} 1}, V_{\mathrm{P} 2}, V_{\mathrm{F} 1}, V_{\mathrm{F} 2}, V_{\mathrm{BCP} 2}$ are the variances of the $\mathrm{P}_{1}, \mathrm{P}_{2}, \mathrm{~F}_{1}, \mathrm{~F}_{2}$, and $\mathrm{BC}_{\mathrm{P} 2}$ populations, $\mathrm{GR}$ is the genotypic range, and $h=(\mathrm{F} 1-\mathrm{P} 2) /(\mathrm{P} 1-\mathrm{P} 2)$, where $\mathrm{P} 1, \mathrm{P} 2$, and $\mathrm{F} 1$ are the mean phenotypic values of the $\mathrm{P}_{1}, \mathrm{P}_{2}$, and $\mathrm{F}_{1}$ populations, respectively. GR used in formulas for $n_{\mathrm{BCP} 2}$ and $n_{\mathrm{F} 2}$ was estimated by two methods: (i) the difference of the parental means and (ii) the phenotypic range of the population variances (1).

The distributions of MLP and uredinium area were plotted for parental, $F_{1}, F_{2}$, and backcross populations. We considered segregation of the backcross or $F_{2}$ populations beyond the range of the parental populations to be evidence of transgressive segregation. We examined models for differences between CI 13227 and L574-1 involving zero, one, or two shared genes. In our models, we assumed that MLP values for a susceptible interaction were 7.5 days based on values presented by Lehman and Shaner $(16,17)$ for the highly susceptible cv. Monon inoculated with wild-type isolates of $P$. triticina.

Assuming that four partially recessive genes condition long latent period in CI 13227 (28) and two partially recessive genes condition long latent period in L-574-1 (13), there are three models for the inheritance of the six genes. (i) There could be no genes in common between L-574-1 and CI 13227 (i.e., six segregating genes in the $F_{2}$ generation). In this model, $F_{1}$ individuals are heterozygous at all six loci. Because partial resistance typically is recessive $(13,28)$, levels of resistance of $F_{1}$ should be lower than those of either resistant parent, barring complications due to modifying genes, epitasis, or the complementation of alleles in the heterozygous state (14). (ii) CI 13227 and L-574-1 could share one gene (i.e., four segregating genes in the $F_{2}$ generation). In this model, $F_{1}$ individuals are significantly more resistant than genotypes with no genes for resistance, such as Monon. Theoretically, $\mathrm{F}_{1}$ individuals may be even more resistant than L-574-1, depending on the effect of the gene in common and the contribution of genes in the heterozygous condition to resistance. (iii) L-574-1 and CI 13227 could share two genes (i.e., two segregating genes in the $\mathrm{F}_{2}$ generation). In this model, there is no transgressive segregation outside the range of CI 13227. $F_{1}$ individuals would be at least as resistant as the less-resistant parent. For each model, the genes could have equal or unequal effects. Each of these models was examined as a possible explanation of our data.

In the one-shared-gene model, we assumed that the shared gene had a major effect on long latent period; therefore, cv. L-574-1 had a major $(b)$ and a minor $(a)$ allele for long latent period. CI 13227 had the same major $(b)$ and three minor alleles $(c, d$, and $e$ ) for long latent period. We assumed that homozygous genotypes $a a, b b, c c, d d$, and $e e$ extended latent period by $0.5,2,1,1$, and 1 days, respectively. The values assigned for the genes in CI 13227 were similar to those assigned by Shaner et al. (28). Gene values for L-574-1 were based on the observation that a susceptible latent period was approximately 7.5 days $(16,17)$. Because the MLP for L-574-1 in our study was approximately 2.5 days longer than for a fully susceptible cultivar, we assumed that the two resistance genes in L-574-1 increased latent period 2.5 days (i.e., this is the total effect of $a a$ and $b b$ ). The latent period of the $\mathrm{F}_{1}$ suggested that the genes contributed unequally to long latent period, and that the shared gene $(b b)$ contributed more than the gene not shared by the two cultivars. Based on $F_{1}$ values, we assumed $b b$ added 2 days to the latent period, whereas $a a$ added only 0.5 day. We assigned the degree of dominance as -0.5 based on data from experiment B and from previous studies (13); hence, if, in the homozygous condition (i.e., $c c$ ), an allele adds 1 day to latent period, then the allele in the heterozygous condition (i.e., $C c$ ) would add 0.25 days to latent period. In this model, L-574-1 had the genotype $a a b b C C D D E E$ and a hypothetical latent period of 10 days (i.e., $7.5+0.5+2+0+0+0$ ). CI 13227 had the genotype AAbbccddee and a hypothetical latent period of 12.5 days (i.e., $7.5+0+2+1+1+1$ ). The cross between CI 13227 and L574-1 would produce $A a b b C c D d E e \mathrm{~F}_{1}$ individuals with a latent period of 10.4 days (i.e., $7.5+0.125+2+0.25+0.25+0.25$ )

To test whether expected results from our model with one shared gene fit our observed data, an average probability distribution was created for both the $\mathrm{BC}_{\mathrm{P} 1}$ and $\mathrm{BC}_{\mathrm{P} 2}$ generations and compared with observed data. Average probability distributions were calculated based on the 16 anticipated genotypes in each of the two backcross populations. For each genotype, a probability distribution for days 5 to 16 was calculated based on a normal distribution and standard deviation estimated from variation in the $F_{1}$ and parent generations. The probability distribution for each expected genotype was combined across all genotypes to create an overall probability of the hypothetical backcross population. In the case of the backcross to L-574-1, this model was used to determine the expected number of plants with a latent period less than that of L-574-1, between L-574-1 and $F_{1}$ values, and above $\mathrm{F}_{1}$ values. For the backcross to $\mathrm{CI} 13227$, we calculated the expected number of plants segregating below $F_{1}$ values, between $\mathrm{F}_{1}$ and CI 13227 values, and above CI 13227 values. To test whether observed data fit expected segregation patterns, $\chi^{2}$ tests were performed.

We calculated linear regression coefficients and intercepts for uredinium area plotted against MLP for $\mathrm{F}_{2}$ and backcross generations. Coefficients of determination $\left(r^{2}\right)$ were calculated and used to describe the commonality of genes governing latent period and uredinium area.

\section{RESULTS}

In both experiments, inoculation with $P$. triticina resulted in 50 to 300 uredinia per 3- to 5-cm-long section of the flag leaf. Based on data from reciprocal crosses, there were no maternal effects for latent period or uredinium area (Table 1). Because no maternal effects were present, the reciprocal crosses from each generation were combined for the remaining data analyses.

The degree of dominance for latent period was -1.11 and -0.50 for experiments $A$ and $B$, respectively. The latent period for the $F_{1}$ generation resembled the latent period for L-574-1 (Fig. 1). Broad-sense heritability was 0.719 and 0.738 for experiments A and $\mathrm{B}$, respectively.

Transgressive segregation was present in the $\mathrm{BC}_{\mathrm{P} 1}, \mathrm{BC}_{\mathrm{P} 2}$, and $\mathrm{F}_{2}$ generations for experiments $\mathrm{A}$ and $\mathrm{B}$ (Fig. 1). In experiment $\mathrm{A}$, latent periods ranged from 7.4 to 17.2 days for the $\mathrm{F}_{2}$ generation. In experiment $\mathrm{B}$, latent periods ranged from 7.9 to 15.8 days for $\mathrm{BC}_{\mathrm{P} 1}, 7.4$ to 15.4 for $\mathrm{BC}_{\mathrm{P} 2}$, and 7.4 to 16.5 days for the $\mathrm{F}_{2}$ generation. Ranges for the parents L-574-1 and CI 13227 were 9.2 to 11.6 and 10.1 to 14.1 days, respectively, in experiment A and 9.1 to 11.9 and 10.8 to 13.6 days, respectively, in experiment B. For experiments $\mathrm{A}$ and $\mathrm{B}$, the gene number estimated from $\mathrm{F}_{2}$ and $\mathrm{BC}_{\mathrm{P} 2}$ populations ranged from 0.3 to 0.6 (parental difference method) or from 5.6 to 9.3 (phenotypic range method) (Table 2).

The two-shared-gene model did not adequately explain the data because of the presence of transgressive segregation. In this model, no $\mathrm{F}_{2}$ individuals were expected to transgress outside the range of CI 13227. However, 6 of 225 plants in experiment A and 10 of 226 plants in experiment B were outside the range of CI 13227. Observed MLP values for the $F_{1}$ generations resembled those expected by this model.

Based on the model with one shared gene of major effect on latent period, we expected 16 genotypes to be present in $\mathrm{BC}_{\mathrm{P} 1}$ and $\mathrm{BC}_{\mathrm{P} 2}$ populations, with MLPs that ranged from 9.6 to 10.8 and 10.3 to 12.6 days, respectively. Specifically, we expected 27 of 70 
$\mathrm{BC}_{\mathrm{P} 1}$ individuals to have MLP values shorter than that of L-574-1, 21 of $70 \mathrm{BC}_{\mathrm{P} 1}$ individuals with MLP between those of L-574-1 and the $\mathrm{F}_{1}$ population, and 22 of $70 \mathrm{BC}_{\mathrm{P} 1}$ individuals with MLP greater than those of the $\mathrm{F}_{1}$. Observed values were 28,16 , and 26, respectively. Observed data fit this distribution $\left(\chi^{2}=1.95, \mathrm{df}=2\right.$, $P=0.38$ ) (Table 3). Similarly, in the $\mathrm{BC}_{\mathrm{P} 2}$ generation, 17, 37, and 15 of 69 individuals were expected to have an MLP below $F_{1}$ values, between $F_{1}$ and CI 13227, and greater than CI 13227, respectively. Observed values were 22,29 , and 18 , respectively. A $\chi^{2}$ test was performed on the expected number of plants segregating in each category versus the observed number of plants in each category. Observed data fit this distribution $\left(\chi^{2}=3.80\right.$, $\mathrm{df}=$ 2, $P=0.15$ ) (Table 3).

In the no-shared-gene model, genotypes $a a$ and $b b$ (from $\mathrm{L}$ 574-1) added 2 and 0.5 days to the latent period and genotypes $c c$, $d d$, ee, and $f f$ (from CI 13227) added 2, 1, 1, 1, and 1 days to the latent period. In this model, expected MLP values for L-574-1, CI 13227 , and $F_{1}$ (heterozygous at all loci, a to f) were $10,12.5$, and
8.9 days, respectively. Although our observed data for parent populations resembled expected data, observed values for the $F_{1}$ population were considerably higher. We also considered this model with genes in L-574-1 having equal effects (i.e., 1.25 days each). In this model, parental values would be the same as those in the model of unequal effects, whereas $F_{1}$ values would be 9.37 days $(=7.5+0.31+0.31+0.5+0.25+0.25+0.25)$. In all scenarios involving the model of no genes in common, observed $F_{1}$ values did not resemble expected $F_{1}$ values.

Uredinium area. Uredinium areas for the $F_{1}$ were slightly larger than the values for the more resistant parent CI 13227 (Fig. 2 ). The degree of dominance ranged from 0 to 0.51 . Broad-sense heritability was 0.73 and 0.36 in experiments $\mathrm{A}$ and $\mathrm{B}$, respectively.

Transgressive segregation was present in the $\mathrm{BC}_{\mathrm{P} 1}, \mathrm{BC}_{\mathrm{P} 2}$, and $\mathrm{F}_{2}$ populations (Fig. 2). In experiment $A$, uredinium areas for the $F_{2}$ ranged from 0.052 to $0.52 \mathrm{~mm}^{2}$. In experiment $\mathrm{B}$, the uredinium area ranged from 0.061 to $0.38 \mathrm{~mm}^{2}$ for $\mathrm{BC}_{\mathrm{P} 1}, 0.024$ to $0.42 \mathrm{~mm}^{2}$

TABLE 1. Tests for maternal effects on latent period and uredinium area of Puccinia triticina in reciprocal crosses involving the $\mathrm{F}_{1}, \mathrm{BC}_{\mathrm{P} 1}$, and $\mathrm{BC}_{\mathrm{P} 2}$ populations derived from a cross between wheat cvs. L-574-1 and CI 13227

\begin{tabular}{|c|c|c|c|c|c|c|c|c|}
\hline \multirow[b]{2}{*}{ Generation, cross } & \multicolumn{4}{|c|}{ Latent period (days) } & \multicolumn{4}{|c|}{ Uredinium area $\left(\mathrm{mm}^{2}\right)$} \\
\hline & No. of plants & Mean & Variance & $P^{\mathrm{a}}$ & No. of plants & Mean & Variance & $P^{\mathrm{a}}$ \\
\hline \multicolumn{9}{|l|}{$\mathrm{F}_{1}$} \\
\hline CI $13227 \times$ L-574-1 & 23 & 10.6 & 1.57 & $\ldots$ & 23 & 0.175 & 0.0024 & $\ldots$ \\
\hline \multicolumn{9}{|l|}{$\mathrm{BC}_{\mathrm{P} 1}$} \\
\hline L-574- $1 \times \mathrm{F}_{1}$ & 61 & 10.1 & 2.57 & 0.617 & 60 & 0.195 & 0.0047 & 0.50 \\
\hline $\mathrm{F}_{1} \times \mathrm{L}-574-1$ & 9 & 9.9 & 0.81 & $\ldots$ & 9 & 0.177 & 0.0051 & $\ldots$ \\
\hline $\mathrm{F}_{1} \times \mathrm{CI} 13227$ & 4 & 11.5 & 3.37 & $\ldots$ & $\ldots$ & $\ldots$ & $\ldots$ & $\ldots$ \\
\hline
\end{tabular}

${ }^{a} P$ value obtained from a $t$ test assuming unequal variances. $P>0.05$ suggests no maternal effects.
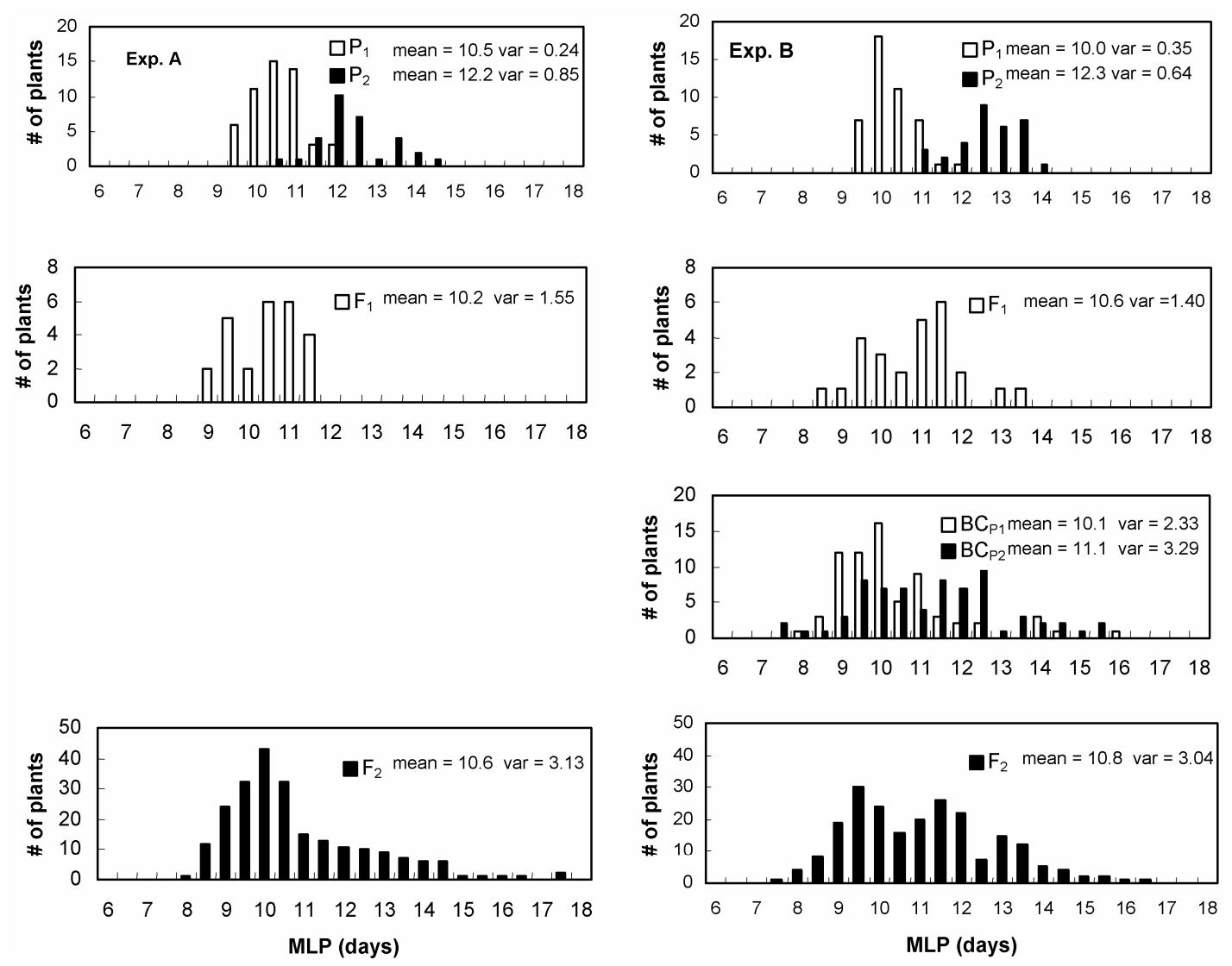

Fig. 1. Frequency distribution of mean latent period for L-574-1 ( $\left.\mathrm{P}_{1}\right), \mathrm{CI} 13227\left(\mathrm{P}_{2}\right), \mathrm{F}_{1}$, and $\mathrm{F}_{2}$ populations in experiment $\mathrm{A}$, and the L-574-1 ( $\left.\mathrm{P}_{1}\right)$, CI 13227 ( $\left.\mathrm{P}_{2}\right)$, $\mathrm{F}_{1}, \mathrm{~F}_{2}, \mathrm{BC}_{\mathrm{P} 1}$, and $\mathrm{BC}_{\mathrm{P} 2}$ populations in experiment $\mathrm{B}$, inoculated with Puccinia triticina. 
for $\mathrm{BC}_{\mathrm{P} 2}$, and 0.019 to $0.42 \mathrm{~mm}^{2}$ for the $\mathrm{F}_{2}$. In experiments $\mathrm{A}$ and $\mathrm{B}$, the gene number estimated from $\mathrm{F}_{2}$ and $\mathrm{BC}_{\mathrm{P} 2}$ populations ranged from 0.1 to 0.2 genes (parental difference method) or from 5.3 to 10 genes (phenotypic range method) (Table 2).

Uredinium area and MLP comparison. The uredinium area and MLP were compared in the $\mathrm{BC}_{\mathrm{P} 1}, \mathrm{BC}_{\mathrm{P} 2}$, and $\mathrm{F}_{2}$ populations. All regressions were significant $(P<0.0001)$. Values for $r^{2}$ indicate that genes controlling latent period explain only 14 to $26 \%$ of the variation in uredinium area. All of the graphs had similar slopes and $y$ intercept values (Fig. 3).

\section{DISCUSSION}

Latent period and uredinium area are components of partial resistance that can be measured reliably when they are examined under controlled conditions in the greenhouse. They are correlated with the rate of rust development in the field $(9,15,25,26,29)$ and, therefore, are useful in characterizing the genetics of partial resistance in cereal crops. Typically, partial resistance in cereals is studied in crosses between susceptible and resistant parents (1$3,8,13,30)$.

CI 13227 has been reported to have a long MLP $(\approx 10.5$ to 12.8 days $)$ and small uredinia $\left(\approx 0.07\right.$ to $\left.0.30 \mathrm{~mm}^{2}\right)(13,16,17$, 28,29 ). Genes of unequal effects (one major and three minor) control latent period in CI 13227 (28). The number of genes that

TABLE 2. Estimates of the number of segregating genes for mean latent period (MLP) and uredinium area of Puccinia triticina in a cross between partially resistant wheat cvs. L-574-1 and CI 13227 calculated from the parental difference and the phenotypic range as measures of the genotypic range

\begin{tabular}{lllll}
\hline & & \multicolumn{3}{c}{ Population } \\
\cline { 3 - 5 } Trait, experiment & Method $^{\mathrm{a}}$ & $\mathrm{BC}_{\mathrm{P} 2}$ & $\mathrm{~F}_{2}$ & Range \\
\hline MLP & & & \\
A & & $\ldots$ & 0.3 & $0-1$ \\
& $\left(\mathrm{P}_{\mathrm{s}}-\mathrm{P}_{\mathrm{s}}\right)^{2}$ & $\ldots$ & 9.3 & $9-10$ \\
B & $(\mathrm{PR})^{2}$ & 0.6 & 0.4 & $0-1$ \\
& $\left(\mathrm{P}_{\mathrm{s}}-\mathrm{P}_{\mathrm{s}}\right)^{2}$ & 7.2 & 5.6 & $5-8$ \\
Area & $(\mathrm{PR})^{2}$ & & & \\
A & & $\ldots$ & 0.1 & $0-1$ \\
& $\left(\mathrm{P}_{\mathrm{s}}-\mathrm{P}_{\mathrm{s}}\right)^{2}$ & $\ldots$ & 5.3 & $5-6$ \\
B & $(\mathrm{PR})^{2}$ & 0.2 & 0.2 & $0-1$ \\
& $\left(\mathrm{P}_{\mathrm{s}}-\mathrm{P}_{\mathrm{s}}\right)^{2}$ & 10.1 & 7.8 & $7-11$ \\
\hline
\end{tabular}

a $\left(\mathrm{P}_{\mathrm{s}}-\mathrm{P}_{\mathrm{s}}\right)^{2}=$ estimate of the genotypic range using the difference between the two parents $\left(\mathrm{P}_{\mathrm{S}}=\mathrm{L}-574-1\right.$ and $\left.\mathrm{P}_{\mathrm{r}}=\mathrm{CI} 13227\right)$, and $(\mathrm{PR})^{2}=$ estimate of genotypic range using the phenotypic range of the segregating population $\left(\mathrm{BC}_{\mathrm{P} 2}\right.$ or $\left.\mathrm{F}_{2}\right)$. control uredinium area in CI 13227 is unknown. Like CI 13227, L-574-1 is also a good source of partial resistance to wheat leaf rust due to its long latent period and small uredinia. Its expression of latent period as reported in the literature is more variable that that of CI 13227 (averages range from $\approx 8.8$ to 12.3 days) (13, $14,16,17)$. Initial and final uredinium area for L-574-1 was reported as 0.12 and $0.51 \mathrm{~mm}^{2}$ (17). Lee and Shaner (13) proposed that two genes of equal effect control latent period in L-574-1. There have been no studies on the genetic control of uredinium area in L-574-1. Our values for MLP (CI $13227=12.2$ and 12.3 days; $\mathrm{L}-574-1=10.0$ and 10.5 days) and uredinium area (CI $13227=0.15$ and $0.19 \mathrm{~mm}^{2} ; \mathrm{L}-574-1=0.25$ and $0.20 \mathrm{~mm}^{2}$ ) are within the ranges reported in the literature for CI 13227 and L-574-1.

Maternal effects for latent period and uredinium area in the $\mathrm{F}_{1}$ and backcross generations were absent in our study. Bjarko and Line (2) also reported the absence of maternal effects in $F_{1}$ and $F_{2}$ generations evaluated for disease intensity of leaf rust on spring wheat. Our estimates of degree of dominance of latent period (i.e., -1.11 and -0.50 ) agreed with previous studies that claim long latent period is a partially recessive trait. Jacobs and Broers (8) reported degree of the dominance in resistant $\times$ resistant crosses of Westphal 12A, Akabuzu, and BH1146 as -0.93 to -1.14 . Lee and Shaner (13) reported a degree of dominance for latent period was -0.50 in a cross between L-574-1 and Suwon 92 (i.e., long latent period was partially recessive). Similarly, Kuhn et al. (11) found that latent period was partially recessive based on skewed frequency distributions of $\mathrm{F}_{3}$ families. We hypothesized that uredinium area also would be partially recessive. However, average uredinium area for $F_{1}$ individuals either resembled values of the more resistant parent or were no different than midparent values (degree of dominance $=0.0$ to 0.51 ). Webster and Ainsworth (32) observed that partial resistance in snap beans (Phaseolus vulgaris) as measured by pustule size was governed by a dominant allele. Kuhn et al. (11) found no dominance for uredinium area (i.e., the mean for $\mathrm{F}_{3}$ families was not significantly different from midparent values). The partial recessiveness of long latent period means that, if intense selection is practiced in an early generation (e.g., the $F_{2}$ ), plants whose progeny would have the desired phenotype would be discarded (28). Therefore, bulk populations should be carried along for several generations, which would allow continued selection for lines with a long latent period.

Although partial resistance is a quantitative trait, it is moderately heritable. Our estimates of broad-sense heritability suggest that 72 to $74 \%$ and 36 to $73 \%$ of the variation in latent period and uredinium area, respectively, is attributable to genetic variation. Shaner et al. (28) estimated broad-sense heritability for long

TABLE 3. Comparison of segregation of latent period of wheat infected with Puccinia triticina between observed and expected models for the $\mathrm{BC}_{\mathrm{P} 1}$ and $\mathrm{BC}_{\mathrm{P} 2}$ generations in a cross between partially resistant cvs. L-574-1 and CI 13227

\begin{tabular}{|c|c|c|c|c|c|c|}
\hline Generation & No. of plants & Range (days) & Observed & Expected $^{\mathrm{a}}$ & $\chi^{2}$ & $P$ \\
\hline$\overline{\mathrm{BC}_{\mathrm{P} 1}^{\mathrm{b}}}$ & 70 & $\begin{array}{c}7.0-9.9 \\
10.0-10.5 \\
10.6-18.0 \\
\ldots\end{array}$ & $\begin{array}{l}28 \\
16 \\
26 \\
\ldots\end{array}$ & $\begin{array}{l}27 \\
21 \\
22 \\
\ldots\end{array}$ & $\begin{array}{c}0.037 \\
1.19 \\
0.73 \\
\sum \chi^{2}=1.95\end{array}$ & $\begin{array}{c}\ldots \\
\ldots \\
\ldots \\
0.376\end{array}$ \\
\hline $\mathrm{BC}_{\mathrm{P} 2}{ }^{\mathrm{c}}$ & 69 & $\begin{array}{c}7.0-10.5 \\
10.6-12.3 \\
12.4-18.0 \\
\ldots\end{array}$ & $\begin{array}{l}22 \\
29 \\
18 \\
\ldots\end{array}$ & $\begin{array}{l}17 \\
37 \\
15 \\
\ldots\end{array}$ & $\begin{array}{c}1.47 \\
1.73 \\
0.60 \\
\sum \chi^{2}=3.80\end{array}$ & $\begin{array}{c}\ldots \\
\ldots \\
\ldots \\
0.149\end{array}$ \\
\hline
\end{tabular}

a Mean latent period values calculated based on a model assuming L-574-1 and CI 13227 have one major gene in common with a -0.5 degree of dominance. L-574-1 has two genes for resistance and CI 13227 has four genes for resistance. The gene $b$ in the homozygous state (i.e., $b b$ ) increases latent period by 2 days and is common to both parents. The additional gene in L-574-1 (i.e., $a$ ) in the homozygous state (i.e., $a a$ ) increases latent period by 0.5 days. In CI 13227 , additional genes $c, d$, and $e$ in the homozygous state increase latent period by 1 day each.

${ }^{b}$ Range 7.0 to 9.9 days is the population segregating below L-574-1, 10.0 to 10.5 days is the population segregating between L-574-1 and $\mathrm{F}_{1}$, and 10.6 to 18.0 days is the population segregating above $\mathrm{F}_{1}$.

${ }^{c}$ Range 7.0 to 10.5 days is the population segregating below $F_{1}, 10.6$ to 12.3 days is the population segregating between $\mathrm{F}_{1}$ and $\mathrm{CI} 13227$, and 12.4 to 18.0 days is the population segregating above CI 13227. 
latent period in a cross between CI 13227 and Suwon 92 as 0.36 and estimated narrow-sense heritability as 0.64 to 0.98 . Bjarko and Line (1) reported narrow-sense heritability ranging from 0.33 to 0.70 for partially resistance, and slightly higher values for broad-sense heritability. Our results agree with previous studies; latent period and uredinium area were moderately to highly heritable traits. The lower values of heritability that generally were observed for uredinium area suggest that this trait may be more difficult than latent period to work with in a breeding program.

In our study, transgressive segregation was observed in the $\mathrm{BC}_{\mathrm{P} 1}, \mathrm{BC}_{\mathrm{P} 2}$, and $\mathrm{F}_{2}$ populations for both latent period and uredinium area. These observations are similar to those of several previous studies $(3,9,14,30)$. The presence of transgressive segregation suggests that CI 13227 and L-574-1 differ in at least some genes for latent period or uredinium area. If both of the genes for long latent period in L-574-1 were present in CI 13227, we would anticipate no segregation outside the range of CI 13227. In the analysis of latent period, the presence and frequency of transgressive segregation indicated that L-574-1 and CI 13227 likely shared only one gene for long latent period (i.e., they differed by four additional genes). Hypothetical models of one major shared gene and four segregating genes fit our data for backcross generations. The MLP values for our $F_{1}$ population resembled values for L-574-1 and could be explained by a shared major gene for long latent period in the homozygous state and additional genes in the heterozygous condition, all of which contribute to long latent period in $F_{1}$ individuals. Similar observations for $F_{1}$ populations were reported by Lee and Shaner (14) and Jacobs and Broers (8)
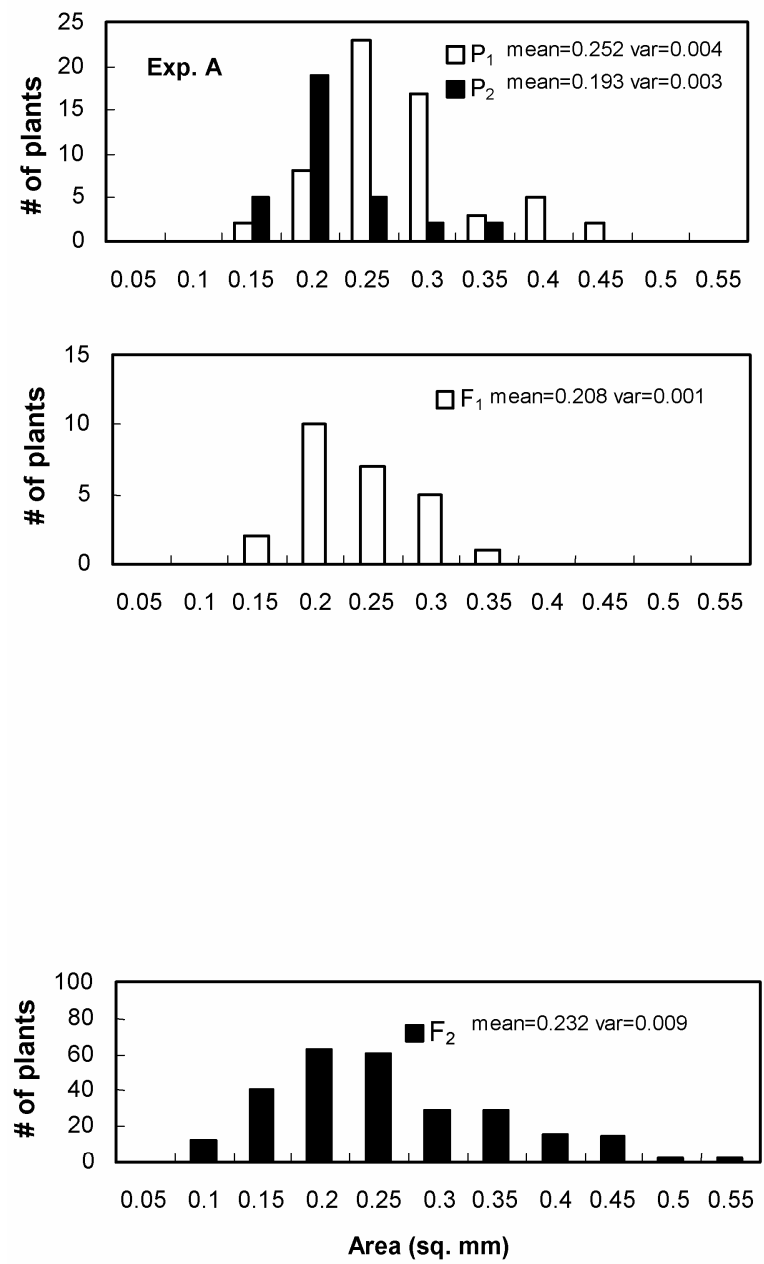

in some resistant $\times$ resistant crosses. In these studies, $F_{1}$ populations from resistant $\times$ resistant crosses resembled the less resistant of the two parents and not susceptible levels. Lee and Shaner interpreted this observation as being due to modifiers, epitasis, or complementation in the heterozygous state. We propose a simpler, more tangible genetic hypothesis, namely that the parents share a gene that contributed greatly to long latent period. By assigning unequal values to shared and unshared genes and assuming a degree of dominance for latent period of -0.5 , we were able to develop hypothetical values for parental and $\mathrm{F}_{1}$ generations that resembled our observed data. Transgressive segregation for uredinium area in the $F_{2}$ and backcrosses, and the values of the $F_{1}$, suggest that CI 13227 and L-574-1 have at least one gene difference for uredinium area.

Our estimates of the number of segregating genes, calculated from genotypic range, were highly variable. In these calculations, we used the phenotypic range and parental difference to estimate genotypic range. Bjarko and Line (1) stated that the phenotypic range method tends to overestimate the number of segregating genes, whereas the parental difference method tends to underestimate the number. They suggest using phenotypic range and parental differences to provide upper and lower estimates of the number of segregating genes, respectively. Based on this rationale, our calculations suggest that there are 0.6 to 5.6 and 0.2 to 5.3 segregating genes for MLP and uredinium area, respectively, in the cross of CI 13227 and L-574-1. The numbers of genes that proposed to segregate in this cross, based on previous work $(13,28)$ and our analysis of patterns of segregation in segregating generations, are within these ranges.
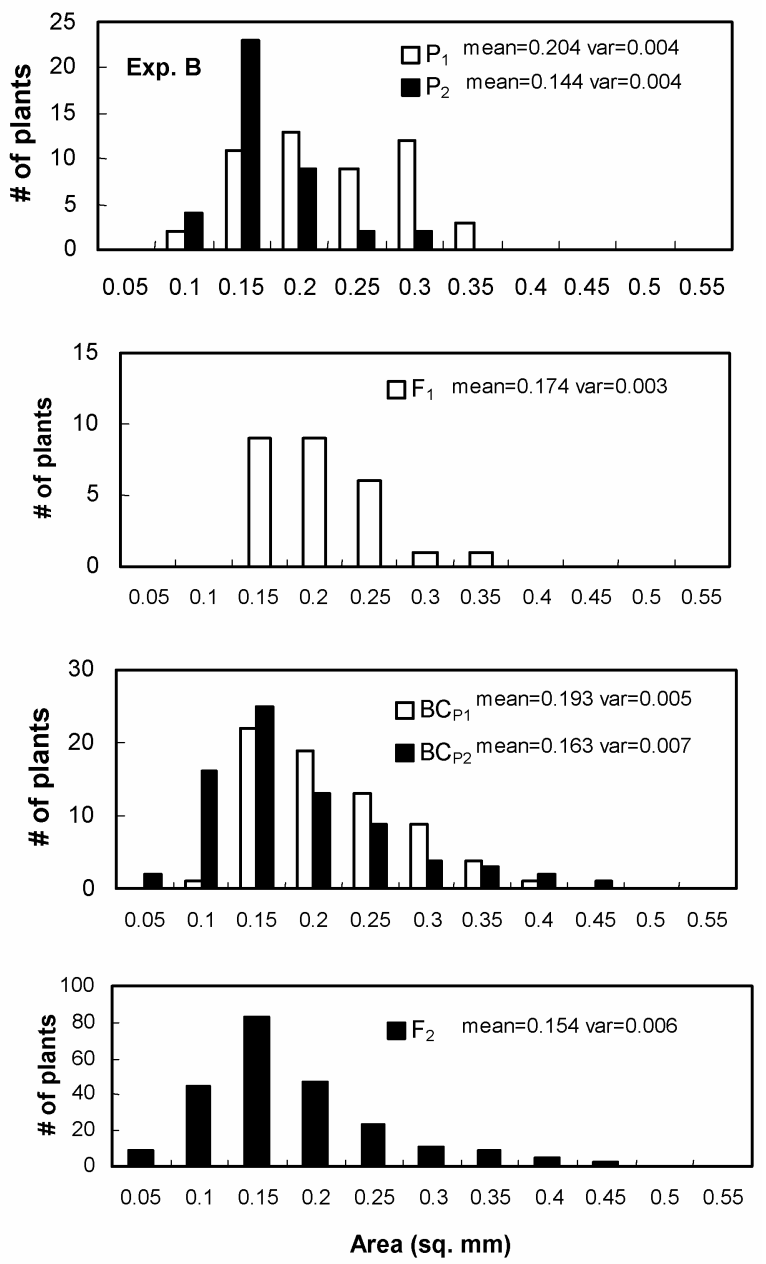

Fig. 2. Frequency distribution of uredinium area for L-574-1 $\left(\mathrm{P}_{1}\right)$, CI $13227\left(\mathrm{P}_{2}\right), \mathrm{F}_{1}$, and $\mathrm{F}_{2}$ populations in experiment $\mathrm{A}$, and the L-574-1 ( $\left.\mathrm{P}_{1}\right)$, CI 13227 $\left(\mathrm{P}_{2}\right), \mathrm{F}_{1}$, $\mathrm{F}_{2}, \mathrm{BC}_{\mathrm{P} 1}$, and $\mathrm{BC}_{\mathrm{P} 2}$ populations in experiment B inoculated with Puccinia triticina. Area (UA) was calculated using the formula UA $=[($ length $)($ width $)(\pi)] / 4$. 

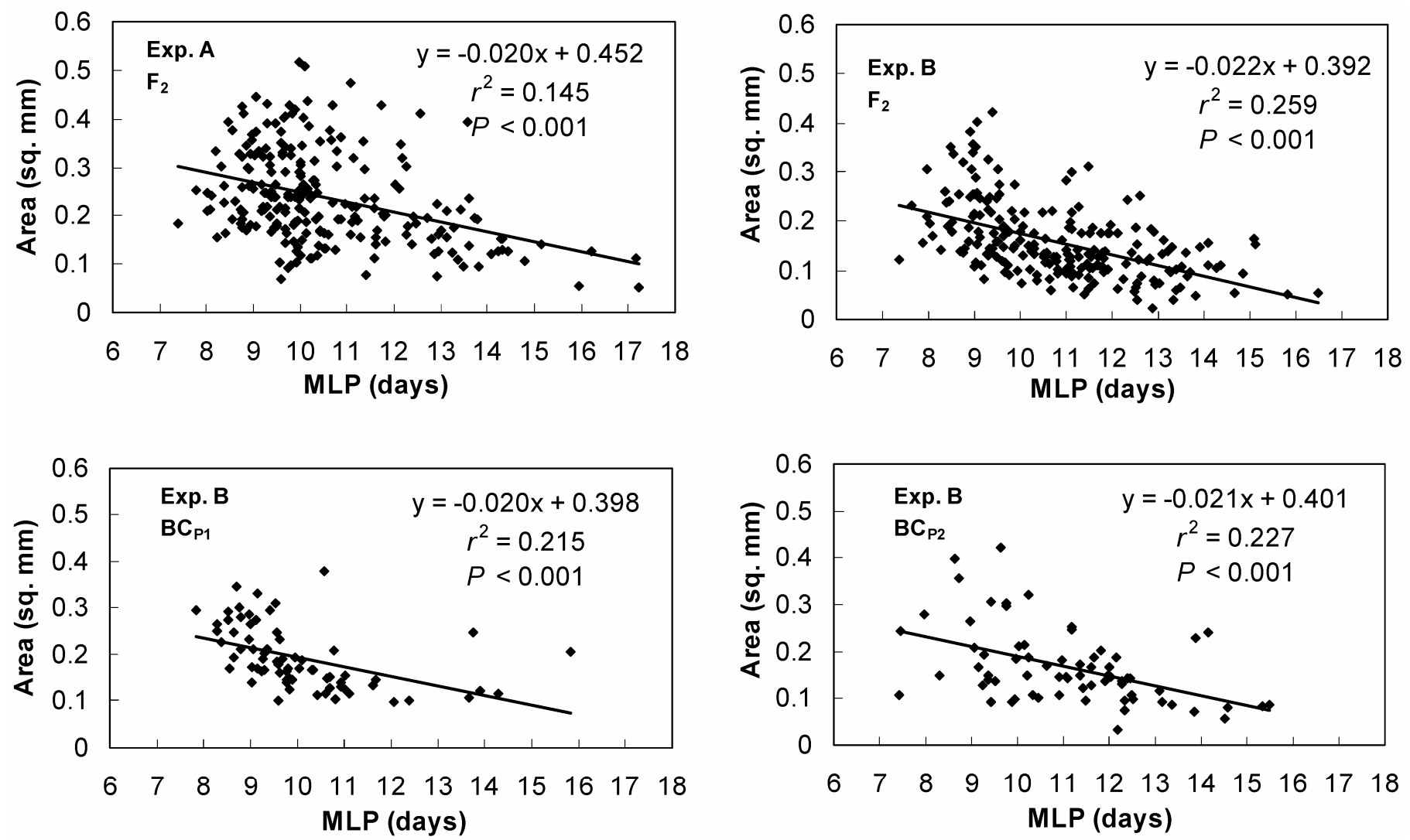

Fig. 3. Relation between uredinium area and mean latent period for $F_{2}$ and backcross generations derived from a cross between L-574-1 and CI 13227 in experiments A and B.

Our study confirms that uredinium area tends to be smaller as latent period is longer $(3,11,13)$. All regression lines between latent period and uredinium area based on the $\mathrm{BC}_{\mathrm{P} 1}, \mathrm{BC}_{\mathrm{P} 2}$, and $\mathrm{F}_{2}$ generations had negative slopes that were significantly different from zero. Coefficients of determination, which ranged from 0.15 to 0.26 , were similar to that reported by Lee and Shaner (13) for $\mathrm{F}_{2}$ plants derived from a L-574-1 $\times$ Suwon 92 cross $\left(r^{2}=0.30\right)$ and those reported by Kuhn et al. (11) for $F_{3}$ plants derived from a Suwon $85 \times$ Suwon 92 cross $\left(r^{2}=0.30\right.$ to 0.40$)$. Based on our results, 15 to $26 \%$ of the variation in uredinium area can be explained by latent period, suggesting that these two components of partial resistance are controlled by at least some of the same genes. A histological study provides some evidence for a common underlying mechanism that extends the latent period and reduces uredinium size (12). The fungus grew slowly in partially resistant cultivars, and took longer to reach a critical size for initiation of uredinia. Shaner (27) also found that uredinium area increased more slowly on partially resistant cultivars. The absence of a strong correlation between latent period and uredinium area implies that separate genes also influence each of these traits.

The sharing of a major gene for latent period between CI 13227 and L-574-1 would have implications for pathogen adaptation and the utility of CI 13227 and L-574-1 as separate sources of resistance. Populations of Puccinia triticina that were selected for greater fitness on partially resistant cv. CI 13227 were also more fit (i.e., larger initial uredinium area and growth rate, and greater sporulation) on the partially resistant cv. L-574-1 to which the pathogen had never been exposed (17). Although this earlier study did not examine the inheritance of partial resistance in either of these cultivars, the cross-adaptation of the fungus to both cultivars suggested that CI 13227 and L-574-1 may share one or more genes for resistance. Here, the data suggest that CI 13227 and L574-1 share one major gene for resistance. This explains why adaptation of the pathogen to CI 13227 resulted in adaptation to L-574-1.

Resistance in L-574-1 and CI 13227 may differ by four genes, suggesting that the genes could be "stacked" to create progeny more resistant than either parent. CI 13227 has one of the longest known latent periods and produces very small uredinia $(16,17$, 28); therefore, stacking the genes of L-574-1 and CI 13227 would produce progeny with a longer latent period and smaller uredinia than any of the more resistant cultivars already observed. Small differences in latent period or lesion size can contribute significantly to resistance in the field, because the increase of disease severity is exponential.

\section{ACKNOWLEDGMENTS}

This research was supported in part by Public Varieties Indiana, Inc., the Purdue Research Foundation, and Otterbein College.

\section{LITERATURE CITED}

1. Bjarko, M. E., and Line, R. F. 1988. Heritability and number of genes controlling leaf rust resistance in four cultivars of wheat. Phytopathology 78:457-461.

2. Bjarko, M. E., and Line. R. F. 1988. Quantitative determination of the gene action of leaf rust resistance in four cultivars of wheat, Triticum aestivum. Phytopathology 78:451-456.

3. Broers, L. H. M., and Jacobs, T. 1989. The inheritance of host plant effect on latency period of wheat leaf rust in spring wheat. II: Number of segregating factors and evidence for transgressive segregation in $F_{3}$ and $F_{5}$ generations. Euphytica 44:207-214.

4. Caldwell, R. M., Roberts, J. J., and Eyal, Z. 1970. General resistance ("slow rusting") to Puccinia recondita f. sp. tritici in winter and spring wheats. (Abstr.) Phytopathology 60:1287.

5. Das, M. K., Rajaram, S., Mundt, C., and Kronstad, W. E. 1992. Inheritance of slow-rusting resistance to leaf rust in wheat. Crop Sci. 32:1452-1456. 
6. Falconer, D. S., and Mackay, T. F. 1996. Pages 108-109 in: Introduction to Quantitative Genetics, 4th ed. Addison Wesley Longman Limited, Essex, England.

7. Gavinlertvatana, S., and Wilcoxson, R. D. 1978. Inheritance of slow rusting of spring wheat by Puccinia recondita f. sp. tritici and host parasite relationships. Trans. Br. Mycol. Soc. 71:413-418.

8. Jacobs, T., and Broers, L. H. M. 1989. The inheritance of host plant effects of latency period of wheat leaf rust in spring wheat. I. Estimation of gene action and number of effective factors in $\mathrm{F}_{1}, \mathrm{~F}_{2}$, and backcross generations. Pages 79-91 in: Histological, Genetical and Epidemiological Studies on Partial Resistance in Wheat to Leaf Rust. L. H. M. Broers and T. Jacobs, eds. Ponson \& Looijen bv, Wageningen, The Netherlands.

9. Johnson, D. A., and Wilcoxson, R. D. 1979. Inheritance of slow rusting of barley infected with Puccinia hordei and selection of latent period and number of uredia. Phytopathology 69:145-151.

10. Kelly, J. D., and Bliss, F. A. 1975. Heritability estimates of percentage seed protein and available methionine and correlations with yield in dry beans. Crop Sci. 15:753-757.

11. Kuhn, R. C., Ohm, H. W., and Shaner, G. 1980. Inheritance of slow leafrusting resistance in Suwon 85 wheat. Crop Sci. 20:655-659.

12. Lee, T. S., and Shaner, G. 1984. Infection processes of Puccinia recondita in slow- and fast-rusting wheat cultivars. Phytopathology 74:1419-1423.

13. Lee, T. S., and Shaner, G. 1985. Oliogenic inheritance of length of latent period in six slow leaf-rusting wheat cultivars. Phytopathology 75:636643.

14. Lee, T. S., and Shaner, G. 1985. Transgressive segregation of length of latent period in crosses between slow leaf-rusting wheat cultivars. Phytopathology 75:643-647.

15. Lehman, J. S., and Shaner, G. E. 1992. Correlation between pathogen fitness components and epidemics of wheat leaf rust. (Abstr.) Phytopathology 82:1161.

16. Lehman, J. S., and Shaner, G. E. 1996. Genetic variation in latent period among isolates of Puccinia recondita $\mathrm{f}$. sp. tritici on partially resistant wheat cultivars. Phytopathology 86:633-641.

17. Lehman, J. S., and Shaner, G. 1997. Selection of populations in Puccinia recondita $\mathrm{f}$. sp. tritici for shortened latent period on a partially resistant wheat cultivar. Phytopathology 87:170-176.

18. Luke, H. H., Barnett, R. D., and Pfahler, R. L. 1975. Inheritance of horizontal resistance to crown rust in oats. Phytopathology 65:631-632.
19. Milus, E. A., and Line, R. F. 1980. Characterization of resistance to leaf rust in Pacific Northwest wheats. Phytopathology 70:167-172.

20. Milus, E. A., and Line, R. F. 1986. Number of genes controlling hightemperature, adult-plant resistance to stripe rust in wheat. Phytopathology 76:93-96.

21. Milus, E. A., and Line, R. F. 1986. Gene action for inheritance of durable, high-temperature, adult-plant resistance to stripe rust in wheat. Phytopathology 76:435-441.

22. Ohm, H. W., and Shaner, G. E. 1976. Three components of slow leaf-rusting at different growth stages of wheat. Phytopathology 66:1356-1360.

23. Parlevliet, J. E. 1976. Partial resistance of barley to leaf rust, Puccinia hordei. III. The inheritance of host plant effect on latent period in four cultivars. Euphytica 25:241-248.

24. Parlevliet, J. E. 1978. Further evidence of polygenic inheritance of partial resistance in barley to leaf rust, Puccinia hordei. Euphytica 27:369-379.

25. Parlevliet, J. E., Leijn, M., and Van Ommeren, A. 1985. Accumulating polygenes for partial resistance in barley to barley leaf rust, Puccinia hordei. II. Field evaluation. Euphytica 34:12-20.

26. Parlevliet, J. E., and Van Ommeren, A. 1975. Partial resistance of barley to leaf rust, Puccinia hordei II. Relationship between field trials, micro plot tests and latent period. Euphytica 24:293-303.

27. Shaner, G. 1983. Growth of uredinia of Puccinia recondita in leaves of slow- and fast-rusting wheat cultivars. Phytopathology 73:931-935.

28. Shaner, G., Buechley, G., and Nyquist, W. E. 1997. Inheritance of latent period of Puccinia recondita in wheat. Crop Sci. 37:748-756.

29. Shaner, G., and Finney, R. E. 1980. New sources of slow leaf rusting resistance in wheat. Phytopathology 70:1183-1186.

30. Shaner, G., Ohm, H. W., and Finney, R. E. 1978. Response of susceptible and slow leaf-rusting wheats to infection by Puccinia recondita. Phytopathology 68:471-475

31. Steel, J. G. D., and Torrie, J. H. 1980. Principles and Procedures of Statistics: A Biometrical Approach, 2nd ed. McGraw-Hill, New York.

32. Webster, D. M., and Ainsworth, P. M. 1988. Inheritance and stability of small pustule reaction of snap beans to Uromyces appendiculatus. J. Am. Soc. Hortic. Sci. 113:938-940.

33. Wilson, J., and Shaner, G. 1989. Inheritance of the leaf rust resistance of four triticale cultivars. Phytopathology 79:731-736.

34. Wright, S. 1968. Evolution and Genetics of Populations. Vol. 1. Genetic and Biometric Foundations, University of Chicago Press, Chicago. 